\title{
ESTÍMULO NO CRESCIMENTO E NA HIDRÓLISE DE ATP EM RAÍZES DE ALFACE TRATADAS COM HUMATOS DE VERMICOMPOSTO. II - EFEITO DA FONTE DE VERMICOMPOSTO ${ }^{(1)}$
}

\author{
Maria Rita Cardoso Rodda ${ }^{(2)}$, Luciano Paqualotto Canellas ${ }^{(3)}$, Arnoldo Rocha \\ Façanha $^{(4)}$, Daniel Basílio Zandonadi ${ }^{(5)}$, José Guilherme Marinho Guerra ${ }^{(5)}$, Dejair \\ Lopes de Almeida ${ }^{(6)}$ \& Gabriel de Araújo Santos ${ }^{(7)}$
}

\begin{abstract}
RESUMO
Um dos fatores mais limitantes para a produção de vermicomposto é a disponibilidade de esterco. Neste trabalho, foi avaliado o efeito da substituição parcial do esterco por bagaço de cana e por resíduos de leguminosa (Gliricidia sepium) na vermicompostagem sobre a qualidade do vermicomposto e sobre a bioatividade dos humatos, avaliadas por meio da análise do crescimento radicular e da atividade das bombas de $\mathrm{H}^{+}$isoladas de raízes de alface. A substituição do esterco por bagaço de cana e por resíduos de leguminosas não acarretou prejuízo às características químicas dos vermicompostos. No entanto, os humatos isolados dos diferentes vermicompostos apresentaram características químicas distintas, tais como: acidez e propriedades óticas distintas. Os humatos produzidos a partir de esterco de bovino e da mistura esterco bovino + bagaço proporcionaram maiores estímulos no crescimento radicular das plantas de alface, sendo os mais indicados para uso na forma solúvel. A inclusão de resíduos de leguminosas no processo de vermicompostagem produziu humatos sem efeito sobre o desenvolvimento das raízes de alface.
\end{abstract}

Termos de indexação: efeitos fisiológicos, substâncias húmicas, agroecologia, $\mathrm{H}^{+}$-ATPase.

\footnotetext{
(1) Parte da Tese de Mestrado do primeiro autor, apresentada à Universidade Federal Rural do Rio de Janeiro -UFRRJ. Recebido para publicação em maio de 2004 e aprovado em julho de 2006.

(2) Doutoranda do Programa de Pós-Graduação em Produção Vegetal da Universidade Estadual do Note Fluminense Darcy Ribeiro - UENF. CEP 28013-602 Campos dos Goytacazes (RJ). E-mail: mrroda@yahoo.com

(3) Professor do Laboratório de Solos, UENF. Bolsista do CNPq. E-mail: canellas@uenf.br

(4) Professor do Laboratório de Biologia Celular e Tecidual, UENF. E-mail: arnoldo@uenf.br

(5) Mestrando do Programa de Pós-Graduação em Produção Vegetal da UENF. E-mail: daniel@uenf.br

(6) Pesquisador da Embrapa-Agrobiologia. Seropédica (RJ). Bolsista do CNPq. E-mail: dejair@cnpab.embrapa.br

(7) Professor do Departamento de Solos da Universidade Federal Rural do Rio de Janeiro -UFRRJ. Bolsista do CNPq. E-mail: gasantos@ufrrj.br
} 


\title{
SUMMARY: IMPROVING LETTUCE SEEDLING ROOT GROWTH AND ATP HYDROLYSIS WITH HUMATES FROM VERMICOMPOST. II - EFFECT OF VERMICOMPOST SOURCE
}

\begin{abstract}
Cattle manure availability is one of the most limiting factors for vermicompost production. The effects of the partial substitution of manure with sugarcane bagasse or residues of Gliricidia sepium on the quality of vermicomposts and the bioactivity of their humates were evaluated by analyzing the root growth and $\mathrm{H}^{+}$-ATPase activity of lettuce seedling roots. The substitutions of manure by sugar cane bagasse and legume cover crops residues did not affect the chemical properties of humates. Humates isolated from the different vermicomposts, however, presented different chemical characteristics, such as acidity and distinct optical properties. Humates isolated from manure and manure + bagasse enhanced growth; these are more adequate for use in soluble form. Humates isolated from vermicompost with legume substitution were ineffective in promoting lettuce root growth.
\end{abstract}

Index terms: physiological effects, humic substances, agroecology, $H^{+}$-ATPase.

\section{INTRODUÇÃO}

Os benefícios do uso de vermicomposto no solo são bem documentados, incluindo o efeito direto das substâncias húmicas sobre o desenvolvimento e metabolismo de várias espécies de plantas (Nardi et al., 2002; Façanha et al., 2002) Em trabalho anterior, foi observado efeito significativo no crescimento de raízes de plântulas de alface, irrigadas com humatos isolados de vermicomposto produzido a partir de esterco de curral (Rodda et al., 2006). Além disso, na concentração de $25 \mathrm{mg} \mathrm{L}^{-1}$ de C de humato de solução, verificou-se um forte estímulo na $\mathrm{H}^{+}$-ATPase vanadato-sensível isolada das raízes das plântulas de alface. A atividade de hidrólise da bomba de $\mathrm{H}^{+}$da plasmalema pode ser utilizada como um marcador efetivo da bioatividade das substâncias húmicas (Canellas et al., 2002), uma vez que desempenha papel essencial no crescimento e na absorção de íons (Cosgrove, 1997).

O uso de humatos a partir de vermicomposto pode ser considerado uma tecnologia artesanal eficiente e facilmente disponível aos agricultores. A matériaprima mais utilizada na vermicompostagem tem sido o esterco bovino. Como a quantidade de esterco é um fator limitante para os produtores de vermicomposto, diversas pesquisas têm avaliado alternativas para substituição parcial ou total desse substrato (Hartenstein et al. 1979; Chan \& Griffiths, 1988; Albanell et al, 1988; Silva, 1992; Aquino et al, 1996).

Aquino (1991) avaliou a atividade reprodutiva das minhocas e constatou que o substrato produzido com a mistura de esterco bovino e bagaço de cana-de-açúcar na proporção 1:1 (v/v) aumentou a população de minhocas em até 30 vezes, apesar de ser o bagaço de cana um resíduo resistente à transformação em virtude da sua elevada relação C/N (Orlando Filho et al., 1983). Assim, o produto final é mais empobrecido em nitrogênio quando comparado ao do esterco. Silva (1992) propôs que a adição de fitomassa de leguminosa no processo de vermicompostagem pode servir como fonte de $\mathrm{N}$ de baixo custo para as minhocas e microrganismos e produção de vermicomposto mais rico neste elemento, uma vez que essas plantas se associam a bactérias fixadoras de $\mathrm{N}_{2}$.

O objetivo deste trabalho foi avaliar o efeito da substituição parcial do esterco de curral por bagaço de cana e por resíduos de leguminosa sobre características químicas do vermicomposto produzido, bem como dos humatos isolados do vermicomposto. A bioatividade dos diferentes humatos foi avaliada por meio do efeito sobre o crescimento de plântulas e sobre a atividade da $\mathrm{H}^{+}$-ATPase isolada de membrana plasmática de raízes de alface.

\section{MATERIAL E MÉTODOS}

\section{Produção do vermicomposto}

O vermicomposto foi preparado em anéis de concreto de $50 \mathrm{~cm}$ de altura e $80 \mathrm{~cm}$ de diâmetro, utilizando esterco bovino, bagaço de cana-de-açúcar e fitomassa de leguminosa (Gliricidia sepium). Cada anel recebeu $200 \mathrm{~L}$ do material de um dos seguintes tratamentos: A - esterco; B - esterco + bagaço de canade-açúcar (1:1, v/v); C- esterco + leguminosa (1:1, v/v); $\mathrm{D}$ - esterco + bagaço de cana-de-açúcar + leguminosa $(2: 1: 1, \mathrm{v} / \mathrm{v} / \mathrm{v})$.

O esterco foi obtido de gado de leite criado em regime semi-extensivo na área da Pesagro - Rio, km 47; o bagaço de cana-de-açúcar, de um vendedor de caldo do comércio local, e a leguminosa, da poda de árvores localizadas no Campo Experimental da Embrapa/ Centro Nacional de Pesquisa em Agrobiologia (CNPAB). Na época da poda, foram colhidas apenas as folhas e hastes com diâmetro inferior a $2 \mathrm{~cm}$.

O esterco foi deixado em pousio, por cerca de 30 dias, até atingir temperatura igual ou inferior a 
$35^{\circ} \mathrm{C}$. O bagaço da cana-de-açúcar e a leguminosa foram triturados em picadeira. Os anéis para a vermicompostagem foram instalados na área do Sistema Integrado de Produção Agroecológica (SIPAFazendinha Agroecológica, km 47). Após a uniformização da umidade dos resíduos orgânicos, a mistura manual dos materiais utilizados como fonte de matéria orgânica nos anéis foi efetuada com base em volume. No fundo de cada anel, foi colocada uma camada de $0,05 \mathrm{~m}$ de pedra britada coberta com saco de ráfia. Este procedimento teve como objetivo a garantia da drenagem nos anéis. Os materiais foram colocados nos anéis e irrigados, ficando em pousio por uma semana, a fim de manter a temperatura abaixo de $40{ }^{\circ} \mathrm{C}$. Em seguida, foram colocadas 200 minhocas (Eisenia foetida) em cada anel e estes cobertos com palha para sombrear e manter a umidade do ambiente.

A maturação dos vermicompostos foi acompanhada pelo monitoramento da temperatura até sua estabilização. Após a estabilização, o vermicomposto foi peneirado para retirada das minhocas e caracterizado quimicamente.

\section{Caracterização química do vermicomposto}

$\mathrm{O}$ vermicomposto estabilizado foi caracterizado por meio das seguintes análises: $\mathrm{C}$ total, pela oxidação em meio ácido com dicromato de potássio e titulação do excesso de CrVI com FeII (Yoemans \& Bremner, 1988); $\mathrm{N}$ total, avaliado pelo micro-Kjeldahl (Camargo

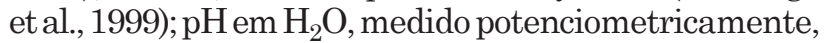
com eletrodos de vidro e calomelano na relação substrato/amostra 1:2,5 (Haimi \& Huhta, 1987); Ca e Mg, pela digestão nitroperclórica e leitura por absorção atômica e K em fotômetro de chama; P total, pela digestão nitroperclórica e dosagem colorimétrica em meio sulfúrico, utilizando ácido ascórbico como redutor (Murphy \& Riley, 1962). O material precursor da vermicompostagem (esterco, resíduo de leguminosa e bagaço de cana) também foi analisado.

\section{Extração dos humatos}

A extração das substâncias húmicas alcalino solúveis do vermicomposto ( $\mathrm{SH}$ ) foi feita com $\mathrm{KOH}$ $0,1 \mathrm{~mol} \mathrm{~L}^{-1}$ na relação vermicomposto/extrator de 1:10 (v/v), por 16 h. Em seguida, as SH foram separadas do resíduo por decantação e sifonação. O excesso de íns foi retirado mediante o uso de resina de troca de íons Amberlite IRA - $120\left(\right.$ forma $\left.\mathrm{H}^{+}\right)$. A dosagem de carbono no humato foi feita por oxidação em meio ácido com dicromato de potássio e determinação do excesso de CrIV com FeII (Yoemans \& Bremner, 1988).

\section{Caracterização química dos humatos}

Determinou-se a composição elementar por meio de um analisador elementar automático Perkin Elmer $2400 \mathrm{em}$ amostras de $10 \mathrm{mg}$ de humatos em duplicata. $\mathrm{O}$ conteúdo de $\mathrm{O}$ foi determinado por diferença, descontado o teor de cinzas obtido com a incineração de três amostras do humato por tratamento em mufla a $700{ }^{\circ} \mathrm{C}$. A acidez total foi obtida pelo método do $\mathrm{Ba}(\mathrm{OH})_{2}$ e a acidez carboxílica, pelo método do $\mathrm{Ca}(\mathrm{OAc})_{2}$, de acordo com Schnitzer \& Gupta (1965). A acidez fenólica foi obtida por diferença. A razão obtida com a absorbância entre 465 e $665 \mathrm{~nm}$ (chamada de relação $\mathrm{E}_{4} / \mathrm{E}_{6}$ ) foi determinada numa solução dos humatos com $4 \mathrm{mg}$ em $10 \mathrm{~mL}$ de $\mathrm{NaHCO}_{3}$ $0,05 \mathrm{~mol} \mathrm{~L}^{-1}$. Os espectros de infravermelho com transformada de Fourier (IV-TF) dos humatos foram obtidos na faixa de 400 a $4.000 \mathrm{~cm}^{-1}$, utilizando-se pastilhas com $1 \mathrm{mg}$ de amostra em $100 \mathrm{mg}$ de $\mathrm{KBr}$, num aparelho Schimadzu, com correção da linha-base com absorção igual a zero em $4.000 \mathrm{~cm}^{-1} \mathrm{e}$ em $2.000 \mathrm{~cm}^{-1}$.

Avaliação do crescimento radicular e atividade de hidrólise da $\mathrm{H}^{+}$-ATPase da fração microssomal isoladas de raízes de plântulas de alface

Sementes de alface (Lactuva sativa var - Regina), obtidas comercialmente, foram esterilizadas, por imersão, numa solução de $\mathrm{NaClO} 0,5 \%$ e mantidas em água, por seis horas, após a lavagem. Em seguida, as sementes foram acondicionadas em papel e germinadas no escuro a $28^{\circ} \mathrm{C}$. As plântulas foram transferidas para copos plásticos que continham meio mínimo com $\mathrm{CaCl}_{2} 2 \mathrm{mM} \mathrm{L}^{-1}$ (tratamento-controle) e meio mínimo complementado com humatos obtidos de vermicomposto de esterco (HV1), de esterco + bagaço de cana-de-açúcar (HV2), de esterco + leguminosa (HV3), e de esterco + bagaço de cana-deaçúcar + leguminosa (HV4), na concentração entre de $25 \mathrm{mg} \mathrm{L}^{-1}$ de $\mathrm{C}$.

O delineamento experimental utilizado, foi inteiramente casualizado, constituído por quatro repetições (com 50 plantas por vaso) e cinco tratamentos. $\mathrm{O}$ pH da solução foi ajustado para 6,0 com solução diluída de $\mathrm{NaOH}$ ou $\mathrm{HCl}$, e a aeração foi forçada por bombeamento contínuo de ar. Após 15 dias de crescimento nestas condições, as plântulas foram coletadas. Para a análise do desenvolvimento radicular, cada repetição constou da média de 10 plântulas de cada vaso. Para a avaliação do número de sítios de mitose e raízes emergidas, cada repetição constou de seis plântulas de cada vaso. Para a preparação microssomal, foram coletadas uma só massa de 30 plântulas de cada um dos vasos, em duas preparações independentes, de acordo com o procedimento descrito em trabalho anterior (Canellas et al., 2002).

\section{RESULTADOS E DISCUSSÃO}

A substituição de parte do esterco por outros tipos de resíduos não acarretou mudanças na reação do 
produto final da vermicompostagem, que apresentou valores de $\mathrm{pH}$ muito similares (Quadro 1). A faixa de valores da relação $\mathrm{C} / \mathrm{N}$ encontrada para os vermicompostos variou de 13 a 26 , com os valores mais baixos para os vermicompostos produzidos com a adição da leguminosa. A adição de bagaço de cana, como era de se esperar, promoveu o maior valor da relação $\mathrm{C} / \mathrm{N}$, mas ainda dentro de limites aceitáveis para utilização direta do vermicomposto como adubo orgânico (Siqueira \& Franco, 1988). O processo de transformação da matéria orgânica foi intenso, promovendo a redução da relação $\mathrm{C} / \mathrm{N}$ inicial de 120 para 26, em torno de 45 dias. A adição de resíduos de leguminosas ao bagaço de cana diminuiu a relação $\mathrm{C} /$ $\mathrm{N}$ para valores abaixo de 20 , com os quais o processo de mineralização do vermicomposto é imediato. Os valores de $\mathrm{Ca}, \mathrm{Mg}, \mathrm{K}$ e $\mathrm{P}$ encontrados nos diversos vermicompostos do presente trabalho encontram-se dentro da faixa apontada por Atiyeh et al. (2002).

A mistura de outros resíduos orgânicos ao esterco para produção de vermicomposto não alterou significativamente a quantidade de humatos extraída (Quadro 1). Os humatos isolados da mistura de esterco + bagaço de cana apresentaram conteúdo maior de C, porém a relação $\mathrm{C} / \mathrm{N}$ foi menor do que a verificada para os humatos isolados de vermicomposto produzido com esterco de curral (Quadro 2). A incorporação de nitrogênio nas substâncias húmicas é um indicador do grau de humificação, uma vez que as reações de condensação moleculares incorporam compostos nitrogenados às estruturas humificadas (Stevenson, 1994). Os humatos isolados dos vermicompostos que tiveram adição de resíduos de leguminosas apresentaram composição elementar bastante similar e com os menores valores da relação $\mathrm{C} / \mathrm{N}$, indicando a possibilidade de incorporação de $\mathrm{N}$ proveniente das leguminosas nas susbtâncias humificadas durante $o$ processo de vermicompostagem.

As relações atômicas $\mathrm{H} / \mathrm{C}, \mathrm{O} / \mathrm{C}$ e $\mathrm{C} / \mathrm{N}$ podem ser usadas para descrever indiretamente algumas características estruturais das substâncias húmicas. Os valores das relações $\mathrm{H} / \mathrm{C} \mathrm{e} \mathrm{O} / \mathrm{C}$ dos humatos foram muito similares entre si (Quadro 2). Entretanto, o humato isolado do vermicomposto produzido com bagaço de cana + esterco apresentou valor da relação $\mathrm{O} / \mathrm{C}$ mais elevado, provavelmente em decorrência da oxidação de grupamentos funcionais presentes na lignina, principal biopolímero estrutural do bagaço. As teorias sobre o processo de humificação foram resumidas por Stevenson (1994) na policondensação de grupos fenólicos oriundos dos resíduos orgânicos, polimerização de açúcares provenientes do metabolismo microbiano e transformação das ligninas.

A razão $\mathrm{E}_{4} / \mathrm{E}_{6}$ pode ser usada para avaliar o grau de maturação das substâncias húmicas (Kononova, 1982). Os humatos extraídos do vermicomposto produzido a partir da mistura de bagaço de cana apresentaram o maior grau de evolução química, uma vez que revelaram o menor valor para a razão $\mathrm{E}_{4} / \mathrm{E}_{6}$ (Quadro 2). O humato isolado do vermicomposto produzido com esterco de curral apresentou o maior valor de relação $\mathrm{E}_{4} / \mathrm{E}_{6}$ e razão $\mathrm{C} / \mathrm{N}$, ou seja, foi o de menor evolução química. Os valores de acidez total dos humatos caracterizam melhor o grau de evolução química, uma vez que são decorrentes diretos de suas características químicas, i.e., quanto maior o valor da acidez, maior o número de moles de $\mathrm{H}^{+}$disponíveis para reações químicas. Os principais grupamentos funcionais que contêm $\mathrm{H}^{+}$são as carboxilas e as hidroxilas fenólicas que são oxidadas até $\mathrm{CO}_{2}$, com o avanço do estádio da humificação. O uso de propriedades ópticas na região do visível para avaliação da humificação teve sua validação por relações empíricas com outras propriedades e não com características químicas envolvidas no fenômeno de absorção de luz no visível. Sistemas eletrônicos do tipo $\pi € \rightarrow € \pi$, que têm transições permitidas entre 465 e $665 \mathrm{~nm}$, não necessariamente podem corresponder à maior presença de estruturas aromáticas (Piccolo, 2002), visto que a presença de outros sistemas conjugados pode dificultar essa interpretação.

O menor valor de acidez total foi verificado no humato isolado do vermicomposto produzido com a mistura bagaço de cana + esterco, indicando ser este

Quadro 1. Caracterização química dos vermicompostos de esterco de curral (V1); esterco de curral + bagaço de cana-de-açúcar (V2); esterco de curral + leguminosa (V3) e esterco de curral + bagaço de cana-deaçúcar + leguminosa (V4)

\begin{tabular}{|c|c|c|c|c|c|c|c|c|c|}
\hline Vermicomposto & $\mathrm{pH}\left(\mathrm{H}_{2} \mathrm{O}\right)$ & C & $\mathbf{N}$ & $\mathrm{C} / \mathrm{N}$ & $\mathbf{C a}$ & $\mathrm{Mg}$ & $\mathbf{P}$ & $\mathbf{K}$ & Humato \\
\hline & & \multicolumn{2}{|c|}{$\mathrm{g} \mathrm{kg}^{-1}$} & & \multicolumn{2}{|c|}{$-\mathrm{cmol}_{\mathrm{c}} \mathrm{dm}^{-3}$} & \multicolumn{2}{|c|}{$\mathrm{mg} \mathrm{dm}^{-3}$} & $\mathrm{~g} \mathrm{~kg}^{-1}$ \\
\hline V1 & $6,3 \mathrm{a}$ & $197 \mathrm{~b}$ & $14,9 \mathrm{a}$ & $13,2 \mathrm{~b}$ & $16,0 \mathrm{a}$ & $13,8 \mathrm{a}$ & $1064 \mathrm{~b}$ & $1140 \mathrm{~b}$ & $107 \mathrm{a}$ \\
\hline V2 & 6,4 a & $288 \mathrm{a}$ & $11,2 \mathrm{a}$ & 25,7 a & $20,3 \mathrm{a}$ & $19,1 \mathrm{a}$ & $2005 \mathrm{a}$ & $1320 \mathrm{a}$ & $72 \mathrm{a}$ \\
\hline V3 & 6,5 a & $212 \mathrm{a}$ & $15,3 \mathrm{a}$ & $13,8 \mathrm{~b}$ & $16,3 \mathrm{a}$ & $19,7 \mathrm{a}$ & 1883 a & 1340 a & $83 \mathrm{a}$ \\
\hline $\mathrm{V} 4$ & $6,4 \mathrm{a}$ & $259 \mathrm{a}$ & $13,9 \mathrm{a}$ & $18,6 \mathrm{ab}$ & $15,5 \mathrm{a}$ & $15,4 \mathrm{a}$ & $2284 \mathrm{a}$ & $1920 \mathrm{a}$ & $103 \mathrm{a}$ \\
\hline
\end{tabular}

Médias seguidas de mesma letra não diferem estatisticamente pelo teste de Tuckey $(\mathrm{P}<0,05)$. 
Quadro 2. Composição elementar, relações atômicas e acidez dos humatos isolados de vermicomposto de esterco (HV1), vermicomposto de esterco + bagaço de cana-de-açúcar (HV2), vermicomposto de esterco + leguminosa (HV3) e vermicomposto de esterco + bagaço de cana-de-açúcar + leguminosa (HV4)

\begin{tabular}{|c|c|c|c|c|}
\hline Propriedade & HV1 & HV2 & HV3 & HV4 \\
\hline $\mathrm{C}\left(\mathrm{g} \mathrm{kg}^{-1}\right)$ & $482 \pm 0,8^{(1)}$ & $532 \pm 1,5$ & $473 \pm 0,6$ & $483 \pm 2,3$ \\
\hline $\mathrm{H}\left(\mathrm{g} \mathrm{kg}^{-1}\right)$ & $48 \pm 0,10$ & $57 \pm 0,2$ & $50 \pm 0,3$ & $44 \pm 3,0$ \\
\hline $\mathrm{N}\left(\mathrm{g} \mathrm{kg}^{-1}\right)$ & $24 \pm 0,40$ & $30 \pm 1,7$ & $25 \pm 0,3$ & $32 \pm 1,1$ \\
\hline $\mathrm{O}\left(\mathrm{g} \mathrm{kg}^{-1}\right)$ & $445 \pm 0,43$ & $380 \pm 0,1$ & $455 \pm 0,4$ & $473 \pm 4,2$ \\
\hline $\mathrm{C} / \mathrm{N}$ & 23,0 & 20,6 & 21,7 & 17,6 \\
\hline $\mathrm{H} / \mathrm{C}$ & 1,2 & 1,3 & 1,3 & 1,1 \\
\hline $\mathrm{O} / \mathrm{C}$ & 1,4 & 1,9 & 1,4 & 1,4 \\
\hline $\mathrm{E}_{4} / \mathrm{E}_{6}$ & 7,5 & 5,7 & 5,9 & 5,7 \\
\hline Acidez total $\left(\mathrm{cmol}_{\mathrm{c}} \mathrm{kg}^{-1}\right)$ & 454,76 & 408,20 & 488,10 & 784,09 \\
\hline Acidez carboxílica $\left(\mathrm{cmol}_{\mathrm{c}} \mathrm{kg}^{-1}\right)$ & 337,50 & 122,73 & 112,27 & 70,51 \\
\hline Acidez fenólica $\left(\mathrm{cmol}_{\mathrm{c}} \mathrm{kg}^{-1}\right)$ & 305,36 & 285,47 & 375,82 & 713,58 \\
\hline
\end{tabular}

(1) Os valores representam a média $(\mathrm{n}=2) \pm$ desvio-padrão.

o material húmico de maior evolução química (Quadro 2). Já o humato isolado do vermicomposto produzido com a mistura de esterco + bagaço + resíduo de leguminosa apresentou o maior valor de acidez total, com incremento de cerca de $92 \%$ a mais de moles de $\mathrm{H}^{+}$que o humato isolado de vermicomposto de esterco + bagaço (Quadro 2). Entretanto, o valor da relação $\mathrm{E}_{4} / \mathrm{E}_{6}$ foi similar ao do humato isolado do vermicomposto produzido com esterco + bagaço de cana, indicando que o uso de propriedades ópticas na região do visível deve ser feito com cautela para avaliar a mistura de ácidos húmicos + ácidos fúlvicos que correspondem aos humatos.

A espectroscopia de IV-TF foi usada neste estudo para avaliar diferenças na estrutura química dos diferentes humatos, uma vez que existe uma região do espectro de infravermelho que é conhecida como região de impressão digital de uma substância (Coulthup et al., 1968). Entre 1.400 e $900 \mathrm{~cm}^{-1}$, somente substâncias com estruturas similares apresentam o mesmo espectro. Na figura 1, são mostrados os espectros de IV-TF, os quais são bastante semelhantes entre si e característicos de substâncias húmicas do tipo 2, conforme a classificação de Stevenson (1994), guardando os humatos mais semelhança com substâncias do tipo fúlvicas que do tipo húmicas. As principais bandas de absorção no IV-TF correspondem à presença de grupos $\mathrm{OH} \mathrm{em} 3.400 \mathrm{~cm}^{-1}$, grupamentos $\mathrm{C}=\mathrm{O}$ de amida (banda 1 ), quinona e $\mathrm{C}=\mathrm{O}$ conjugado, $\mathrm{C}=\mathrm{C}$ aromático $-\mathrm{COO}^{-}\left(1.600 \mathrm{~cm}^{-1}\right)$; deformação de grupos $\mathrm{OH}$ e $\mathrm{OH}$ fenólico, deformação simétrica de $\mathrm{C}-\mathrm{H}$ de grupos $\mathrm{CH}_{2}$ e $\mathrm{CH}_{3}$, estiramento assimétrico $\mathrm{COOH}$ (entre 1.387 e $1.390 \mathrm{~cm}^{-1}$ ); estiramento C-O$\mathrm{H}\left(\mathrm{em} 1.200 \mathrm{~cm}^{-1}\right)$; presença de $\mathrm{C}-\mathrm{O}$ em carboidratos $\left(1.134-1.095 \mathrm{~cm}^{-1}\right)$. Estas atribuições foram baseadas nos trabalhos prévios de Coultup et al. (1968); Bellamy (1975) e Nakanish (1962).
As plântulas de alface tratadas com humatos isolados de vermicomposto produzidos com esterco bovino e com a mistura com bagaço de cana mostraram desenvolvimento radicular significativamente superior ao do controle (Figura 2). Os humatos extraídos de esterco de curral e esterco de curral + bagaço de canade-açúcar proporcionaram acréscimos de 180 e $190 \%$, na área radicular, e de 150 e $140 \%$, no comprimento total radicular, respectivamente, em relação ao controle. Com a adição de resíduos de leguminosas, o incremento foi menor na mistura com esterco bovino e não-significativo na mistura resíduo de leguminosa + esterco + bagaço. Para promoção de desenvolvimento do sistema radicular de alface, os humatos mais efetivos foram o de esterco bovino e o de esterco bovino + bagaço de cana.

O humato isolado de vermicomposto de esterco bovino, seguido do humato isolado do vermicomposto produzido a partir da mistura de esterco + bagaço de cana, promoveu a maior hidrólise de ATP (Figura 3). Os demais humatos não tiveram efeito sobre a $\mathrm{H}^{+}$ATPase da fração microssomal de raízes de alface. É possível observar uma correspondência entre o estímulo no crescimento radicular da alface e a atividade das $\mathrm{H}^{+}$-ATPase isoladas da membrana plasmática de raízes das alfaces. De acordo com a "teoria do crescimento ácido", o íon hidrogênio atua como um intermediário entre à auxina e o afrouxamento da parede celular; a fonte de íons hidrogênio é a $\mathrm{H}^{+}$. ATPase de membrana plasmática, cuja atividade é aumentada em resposta a auxina (Taiz \& Zeiger, 2004). Canellas \& Façanha (2002) mostraram evidências de que ácidos húmicos isolados de vermicomposto apresentam compostos semelhantes a auxinas na sua estrutura complexa e promovem a síntese de $\mathrm{H}^{+}$-ATPase na membrana plasmática, bem como o crescimento de raízes de milho. Canellas \& 

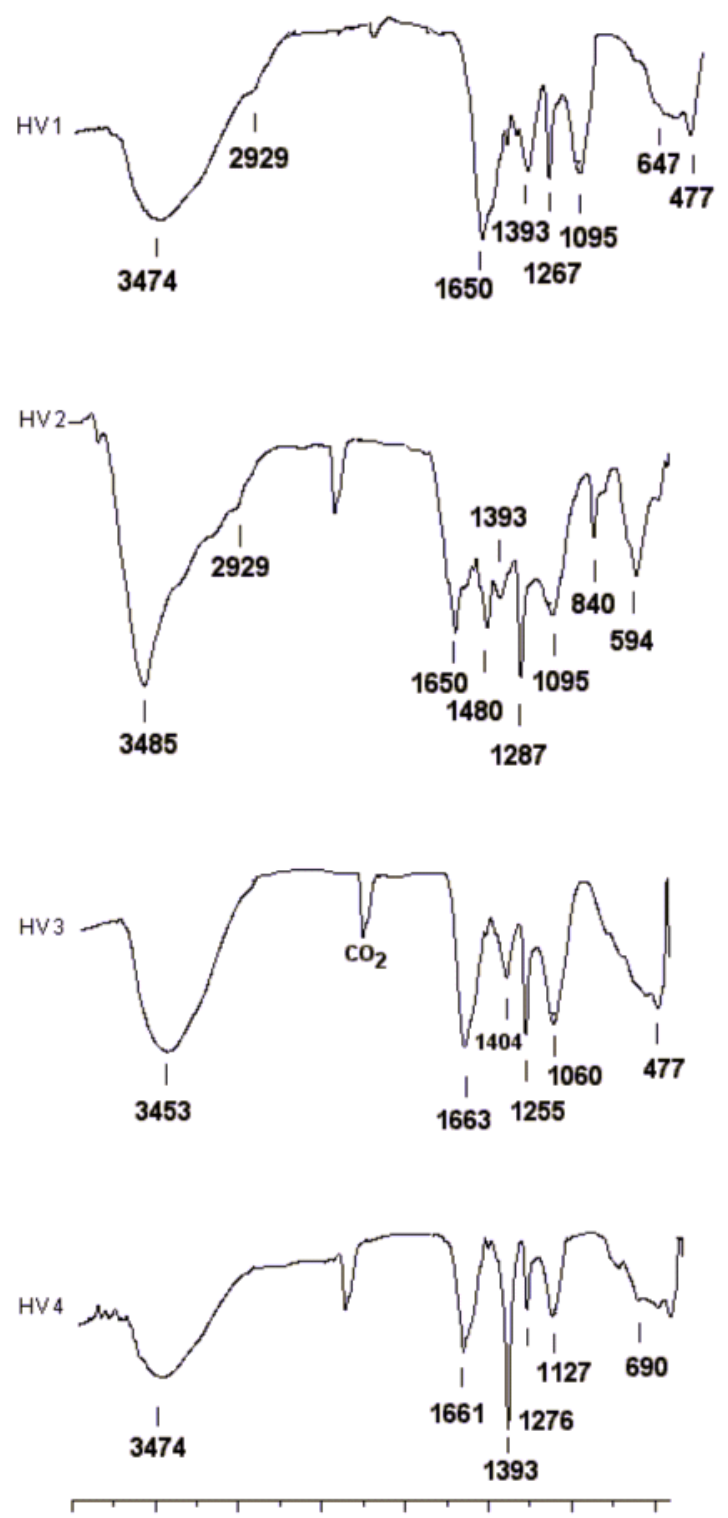

Figura 1. Espectros na região de infravermelho com transformada de Fourier $\left(\mathrm{em} \mathrm{cm}^{-1}\right)$ dos humatos extraídos de vermicomposto de esterco de curral (HV1), de esterco de curral + bagaço de cana-de-açúcar (HV2), de esterco de curral + folhas de leguminosas (HV3) e de esterco de curral + bagaço de cana-de-açúcar + folhas de leguminosas (HV4)

Façanha (2004) verificaram que ácidos húmicos da camada superficial de um Argissolo são capazes de estimular mais o crescimento radicular e a atividade da $\mathrm{H}^{+}$-ATPase de membrana plasmática do que os ácidos fúlvicos e do que os ácidos húmicos isolados da subsuperfície. Observaram esses autores que substâncias húmicas com maior grau de humificação, avaliado pela composição elementar, acidez total e relação $\mathrm{E}_{4} / \mathrm{E}_{6}$, apresentaram maior bioatividade (Canellas \& Façanha, 2004).
Neste trabalho, verificou-se que a adição de leguminosas no resíduo para a vermicompostagem diminuiu a quantidade de esterco utilizada no processo, sem acarretar perdas ou modificações significativas na quantidade de nutrientes do vermicomposto. No entanto, a bioatividade dos humatos isolados dos vermicompostos produzidos a partir da incorporação de resíduos de leguminosas foi menor do que a dos humatos isolados do vermicomposto de esterco de curral e de esterco + bagaço de cana-deaçúcar. Na forma líquida, estes humatos foram mais eficientes na estimulação do sistema radicular de alface. Piccolo et al. (1992) encontraram uma correlação significativa e positiva entre o conteúdo de grupos $\mathrm{CO}_{2} \mathrm{H}$ e a atividade de promoção do crescimento

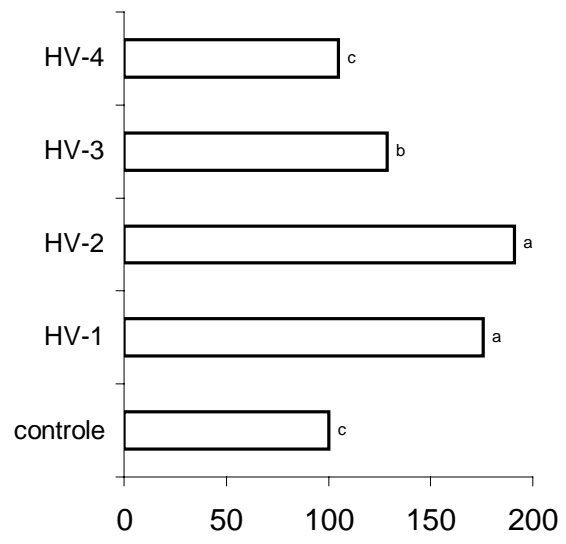

(a)

COMPRIMENTO RADICULAR RELATIVO, \% ${ }^{1}$

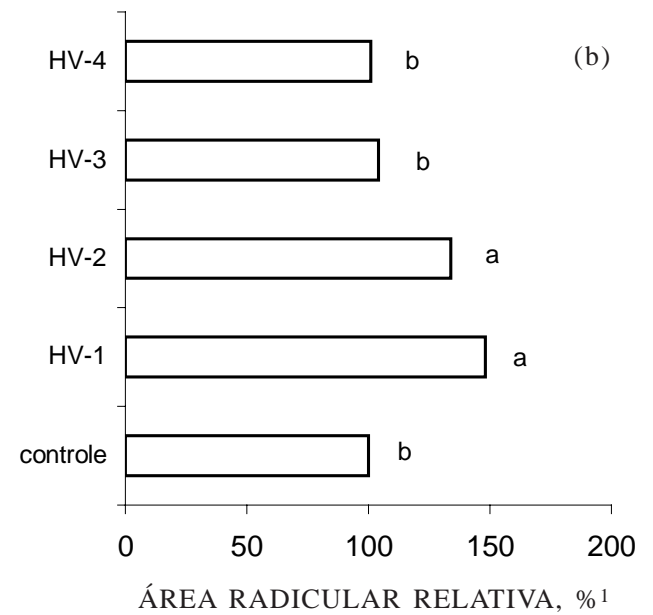

Figura 2. Incremento na área radicular (a) e no comprimento total de raízes (b) de plântulas de alface tratadas com $25 \mathrm{mg} \mathrm{L}^{-1}$ de $\mathrm{C}$ de humatos extraídos de vermicomposto de esterco de curral (HV1), de esterco de curral + bagaço de cana de açúcar (HV2), de esterco de curral + folhas de leguminosas (HV3) e de esterco de curral + bagaço de cana de açúcar + folhas de leguminosas (HV4). Médias seguidas de mesma letra não diferem significativamente pelo teste de Tukey $(\mathrm{P}<0,05)$. 
radicular por substâncias húmicas de baixa massa/ tamanho molecular, como observado anteriormente por Schnitzer \& Poapst (1967). De modo contrário, neste trabalho, os humatos que apresentaram acidez mais elevada foram os que menos estimularam a atividade de crescimento das raízes e de hidrólise de ATP (Quadro 2, Figura 3). Todavia, observou-se que a relação entre a acidez e a atividade de hidrólise não foi estatisticamente significativa. A relação entre a estrutura das substâncias húmicas e sua atividade de estímulo/inibição em processos metabólicos e eventos fisiológicos ainda não foi clara. As características químicas responsáveis pela bioatividade dos humatos ainda não são bem estabelecidas e deverão ser objeto de futuros trabalhos.

\section{CONCLUSÕES}

1. Os humatos extraídos dos vermicompostos produzidos com diversas fontes de matéria orgânica apresentaram características químicas distintas, bem como diferente bioatividade, indicando a possibilidade de uma relação ainda não bem esclarecida entre estrutura e bioatividade dos humatos.

2. Os humatos produzidos a partir de esterco bovino e da mistura esterco bovino + bagaço de cana-deaçúcar proporcionaram estímulos maiores no crescimento radicular das plantas de alface, sendo os mais indicados para uso na forma solúvel. A inclusão de resíduos de leguminosas no processo de vermicompostagem produziu humatos sem efeito sobre o desenvolvimento das raízes de alface.

\section{LITERATURA CITADA}

ALBANELL, E.; PLAILATS, J.;CABRERO, T. \& CAPELLAS, M. Composicion química del estiercol de vaca fresco y maduro durante el vermicompostaje. In: CONGRESSO DE BIOLOGIA AMBIENTAL, 1988, Barcelona. Anais. Barcelona, Universidad Autonoma de Barcelona, 1988. p.247-252.

AQUINO, A.M. Vermicompostagem de esterco bovino e bagaço de cana-de-açúcar inoculado com bactérias fixadoras de $\mathrm{N}_{2}$ (Acetobacter diazotrophicus). Seropédica, Universidade federal Rural do Rio de Janeiro, 1991. 246p. (Tese de Mestrado)

AQUINO, A.M. Vermicompostagem: caracterização da demanda e alternativas de substratos enriquecidos com leguminosas e fósforo. Seropédica, Universidade Federal Rural do Rio de Janeiro, 1996. (Tese de Doutorado)

ATIYEH, R.M.; LEE, S.; EDWARDS, C.A.; ARANCON, N.Q. \& METZGER, J.D. The influence of humic acids derived from earthworm-processed organic wastes on plant growth. Bio. Technol., 84:7-14, 2002.

BELLAMY, L.J. The infrared spectra of complex molecules. London, Chapman \& Hall, 1975.

CAMARGO, F.A.O.; GIANELLO, C. \& RHEINHEIMER, A. Fracionamento do N, P, e S orgânicos. In: CAMARGO, F.A.O. \& SANTOS G.A., eds. Fundamentos da matéria orgânica do solo: Ecossistemas tropicais e subtropicais. Porto Alegre, Gênesis, 1999. p.297-298.

CANELLAS, L.P. \& FAÇANHA, A.R. Chemical nature of soil humified fractions and their bioactivity. Pesq. Agropec. Bras., 39:233-240, 2004.

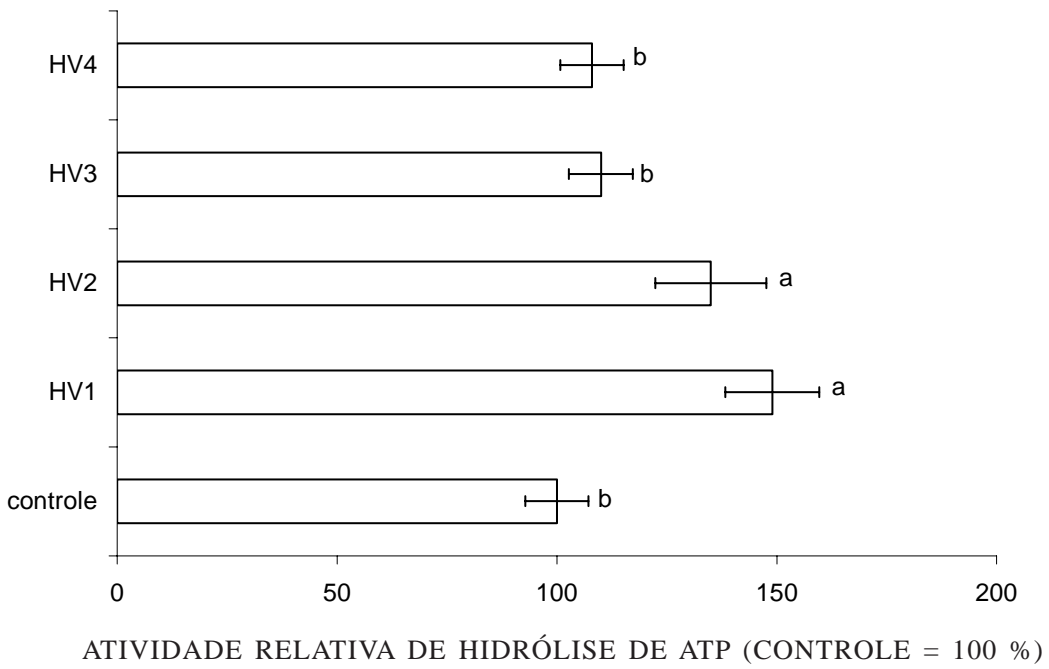

Figura 3. Estímulo da atividade vanadato sensível de hidrólise de ATP da fração microssomal extraída de raízes de alface tratadas com $25 \mathrm{mg} \mathrm{L}^{-1}$ de $\mathrm{C}$ de humatos extraídos de vermicomposto de esterco de curral (HV1), de esterco de curral + bagaço de cana de açúcar (HV2), de esterco de curral + folhas de leguminosas (HV3) e de esterco de curral + bagaço de cana de açúcar + folhas de leguminosas (HV4). Os valores das médias são referentes a duas preparações independentes \pm desvio-padrão. As médias seguidas de mesma letra não diferem significativamente pelo teste Tukey $(\mathrm{P}<0,05)$. 
CANELLAS, L.P.; OLIVARES, F.L.; FAÇANHA, A.L.O. \& FAÇANHA, A.R. Humic acids isolated from earthworm compost enhance root elongation, lateral root emergence, and plasma membrane $\mathrm{H}^{+}$-ATPase activity in maize roots. Plant Physiol., 130:1951-1957, 2002.

CHAN, P.L.S. \& GRIFFITHS, D.A. The vermicomposting of pre-treated pig manure. Biol. Wastes, 24:57-69, 1988

COLTHUP, N.B.; DALY, L.H. \& WIBERLEY, S.E. Introduction to infrared and Raman spectroscopy. .New York, Academic, 1968. 510p.

COSGROVE, D.J. Relaxation in a high-stress environment: The molecular bases of extensible cell walls and cell enlargement. Plant Cell, 9:1031-1041, 1997.

FAÇANHA, A.R.; FAÇANHA, A.R.; OLIVARES, F.L.; VELLOSO, A.C.X.; BRAZ-FILHO, R.; SANTOS, G.A. \& CANELLAS, L.P. Bioatividade de ácidos húmicos: efeitos sobre o desenvolvimento de prótons. Pesq. Agropec. Bras., 37:1301-1310, 2002.

HAIMI, J. \& HUHTA, V. Comparison of composts produced from videntical waster by "vermiestabilization" and conventional composting. Pedologia, 30:137-144, 1987.

HARTENSTEIN, R.; NEUHAUSER, E.F. \& KAPEAN, D.L. Reprodutive potencial of earthworms Eisenia foetida. Oecologia, 43:329-340, 1979.

KONONOVA, M.M. Materia orgánica del suelo: su naturaleza, propriedades y métodos de investigación). Barcelona, Oikos-Tau, 1982. 364p.

MURPHY, J. \& RILEY, J.P. A modified single solution method for the determination of phosphate in natural waters. Anal. Chim. Acta, 27:31-36, 1962.

NAKANISH, K. Infrared absortion spectroscopy. Tokyo, Nankonda, 1962. 233p

NARDI, S.; PIZZEGHELLO, D.; MUSCOLO, A. \& VIANELLO, A. Physiological effects of humic substances on higher plants. Soil Biol. Biochem., 34:1527-1536, 2002.
ORLANDO FILHO, J.; SILVA, G.M. \& LEME, E.J.A. Utilização agrícola dos resíduos da agroindústria canavieira. In: ORLANDO FILHO, J., ed. Nutrição e adubação de canade-açúcar no Brasil. Piracicaba, Planalsucar, 1983. p.229264.

PICCOLO, A. The supramolecular structure of humic substances: a novel understanding of humus chemistry and implications in soil science, Adv. Agron., 75:57-133, 2002.

PICCOLO, A.; NARDI, S. \& CONCHERI, G. Structural characteristics of humic substances as related to nitrate uptake and growth-regulation in plant-systems. Soil Biol. Biochem., 24:373-380, 1992.

RODDA, M.R.C.; CANELLAS, L.P.; FAÇANHA, A.R.; ZANDONADI, D.B.; GUERRA, J.G.M.; ALMEIDA, D.L. \& SANTOS, G.A. Estímulo no crescimento e na hidrólise de ATP em raízes de alface tratadas com humatos de vermicomposto I. efeito de doses de humatos. R. Bras. Ci. Solo, 30:649-656, 2006.

SCHNITZER, M. \& GUPTA, U.C. Determination of acidity in soil organic matter. Soil Sci. Am. Soc. Proc., 29:274-277, 1965.

SCHNITZER, M. \& POAPST, P.A. Effect of soil humic compound on root initiation. Nature, 11:598-599, 1967.

SILVA, V.F. Vermicompostagem utilizando esterco e palha enriquecida com $\mathrm{N}$ e P: processo de produção e avaliação para a cultura da cenoura (Daucus carota L.). Itaguaí, Universidade Federal Rural do Rio de Janeiro, 1992.116p. (Tese de Mestrado)

SIQUEIRA, J.O. \& FRANCO, A.A. Biotenologia do solo: fundamentos e perspectivas. Brasília, Ministério da Educação, ABEAS, ESAL-FAEP, 1988. 236p.

STEVENSON, J.F. Humus chemistry: genesis, composition, reactions. New York, John \& Wiley, 1994. 496p.

TAIZ, L. \& ZEIGER, E. Fisiologia vegetal. Porto Alegre, Artmed, 2004. $719 p$

YOEMANS, J.C. \& BREMNER, J.M. A rapid and precise method for routine determination of organic carbon in soil. Comm. Soil Sci. Plant Anal., 19:1467-1476, 1988. 